Article

\title{
A Universal Early Parenting Education Intervention in Community-Based Primary Care Settings: Development and Installation Challenges
}

\author{
Grainne Hickey*, Sinead McGilloway, Yvonne Leckey@ and Ann Stokes \\ Department of Psychology, National University of Ireland Maynooth, John Hume Building, North Campus, \\ Maynooth, Co. Kildare W23 F2H6, Ireland; Sinead.McGilloway@mu.ie (S.M.); Yvonne.Leckey@mu.ie (Y.L.); \\ Ann.Stokes@mu.ie (A.S.) \\ * Correspondence: Grainne.Hickey@mu.ie
}

Received: 31 July 2018; Accepted: 16 October 2018; Published: 20 October 2018

check for updates

\begin{abstract}
Prevention and early intervention programmes, which aim to educate and support parents and young children in the earliest stages of the family lifecycle, have become an increasingly popular policy strategy for tackling intergenerational disadvantage and developmental inequality. Evidence-based, joined-up services are recommended as best practice for achieving optimal outcomes for parents and their children; however, there are persistent challenges to the development, adoption and installation of these kinds of initiatives in community-based primary health care settings. In this paper, we present a description of the design and installation of a multi-stakeholder early parenting education and intervention service model called the Parent and Infant (PIN) programme. This new programme is delivered collaboratively on a universal, area-wide basis through routine primary care services and combines standardised parent-training with other group-based supports designed to educate parents, strengthen parenting skills and wellbeing and enhance developmental outcomes in children aged 0-2 years. The programme design was informed by local needs analysis and piloting to establish an in-depth understanding of the local context. The findings demonstrate that a hospitable environment is central to establishing interagency parenting education and supports. Partnership, relationship-building and strategic leadership are vital to building commitment and buy-in for this kind of innovation and programme implementation. A graduated approach to implementation which provides training/education and coaching as well as organisational and administrative supports for practice change, are also important in creating an environment conducive to collaboration. Further research into the impact, implementation and cost-effectiveness of the PIN programme will help to build an understanding of what works for parents and infants, as well as identifying lessons for the development and implementation of other similar complex prevention and intervention programmes elsewhere. This kind of research coupled with the establishment of effective partnerships involving service providers, parents, researchers and policy makers, is necessary to meeting the challenge of improving family education and enhancing the capacity of family services to help promote positive outcomes for children.
\end{abstract}

Keywords: parent education; child and family service; collaboration; interagency; evidence-based practice; implementation

\section{Introduction}

Global evidence suggests that 250 million children worldwide will fail to reach their potential due to social and economic adversity and inequality [1]. Supporting parents and infants from the earliest stages of the family lifecycle is now recognised as a crucial public policy priority. Indeed, 
many countries have developed, or are in the process of developing, policies and initiatives to tackle developmental inequality and disadvantage which are aimed at educating parents in the importance of nurturing their children and promoting mental health and wellbeing in families [2,3]. The nature and extent of parental knowledge in relation to child development and parenting practices is a crucial consideration. Parenting knowledge encompasses a parents' understanding of, and attitudes towards, child development, as well as an awareness of practices and strategies which can promote child health and wellbeing [4,5]. Research has demonstrated that superior parenting knowledge is related to healthy child development and positive socioemotional wellbeing. An accumulation of evidence from randomised controlled trials and meta-analyses has also shown that high quality prevention and early intervention which focuses on strengthening parenting knowledge and skills, can help to improve parent-infant relationships and child cognitive, behavioural, social and emotional development outcomes [6-10]. Evidence also suggests that these parent-focused programmes allow children to fulfil their potential and can contribute to better outcomes later in life, including greater educational achievement, better occupational status, reduced reliance on welfare and improved health outcomes, as well as a lower-risk of criminality, antisocial behaviour, substance abuse, risky sexual behaviour, early parenthood and psychopathology [11-13]. Early intervention and prevention programmes have also been found to be cost-effective and substantial social and economic benefits can be generated through effective early intervention [14,15].

Evidence-based parenting programmes can involve home-visiting and group- or centre-based provisions. However, despite the evidence base underpinning the importance of positive parenting and child development and wellbeing, there remain significant challenges to ensuring that families receive appropriate, effective and timely supports, particularly during the critical first 1000 days of a child's life [16]. Most notably, recommendations for best practice in the delivery of early childhood development services involve integrated, multisectoral evidence-based interventions which promote holistic, child-focused approaches and multiple stakeholder partnerships [16]. Thus, the implementation of evidence-based parent education programmes requires significant practice innovation amongst community-based primary health care practitioners (e.g., health visitors, public health nurses, family support workers), including the collaborative provision of parent and child supports. International policy in child services has long promoted the importance of interagency efforts for improving health and care service provisions for parents and young children. Nevertheless, there are significant barriers to such innovation in child and youth services $[17,18]$. The uptake and implementation of evidence-based programmes across family services has been found to be inconsistent and limited [19] and efforts to establish partnership working have often been beset with failure $[20,21]$. Thus, a key challenge for future prevention and early intervention services involves the articulation of effective strategies and approaches aimed at ensuring that all parents and their young children have available to them, evidence-based, coordinated supports which can enhance family wellbeing and help to address social exclusion and disadvantage [16].

Interagency services and supports may range from a low level of consultation and/or joint decision making to more collaborative models of joint working [22], whilst integrated models may involve in-depth shared work in relation to a client or a group of clients [23]. Benefits for prevention and early intervention initiatives have been cited as including increased service efficiency and equity [24,25], as well as increased practitioner access to knowledge, enhanced social capital and staff capacity development $[26,27]$. However, barriers to collaborative partnerships in child and youth services have also been identified and include high staff turnover, insufficient knowledge of partners, lack of commitment and buy-in, a dearth of resources and/or capacity for partnership working, and resistance and conflict amongst partners, incompatible ideologies and agency cultures [28,29]. Facilitating factors, on the other hand, include good communication and understanding across agencies/professionals; joint training; the presence of protocols for interagency working; leadership and a supportive culture; co-location; and positive working relationships between professionals [30,31]. 
To date, a number of systematic reviews have identified the factors which positively or negatively influence partnership working in the children's services sector [32,33], as well as in the broader field of health and social care [30]. Nevertheless, there remain only limited case examples which explore "real world" collaborative implementation efforts and the experiences of stakeholders therein. This kind of community-based research is needed to facilitate the identification and selection of implementation strategies and drivers which support effective collaborative implementation in parent intervention [34-36].

In this paper, we provide an overview of the development and setting up of a multi-stakeholder early parenting education and support model, the Parent and Infant (PIN) programme. We identify and describe the processes and strategies that informed the design of the programme and the experiences of stakeholders involved in its installation, with a view to identifying the facilitating and inhibitive factors which influenced both its roll-out and the nature and extent of partnership working in the initial phases of implementation.

\section{The Parent and Infant Programme}

The Parent and Infant (PIN) programme is a complex, group-based early parenting intervention which was developed in Ireland by an NGO called Archways (a charitable organisation which aims to promote and support the implementation of evidence-based programmes in Ireland), in collaboration with Public Health Nurses (PHNs) and other community-based organisations. The PIN service model combines a range of developmentally-appropriate parent and infant supports that are delivered in a single intervention process from birth to 2 years of age (See Figure 1). The content of the programme is designed to be flexible in the sense that content and delivery can be tailored to parent/community needs, but it also has standardised core elements including two Incredible Years (IY) parenting programmes [37]. Parents who have recently given birth are offered a series of supports including the IY Parent and Baby programme (IYPBP) [38], an 8-week behavioural parent training programme. This is delivered on alternate weeks in conjunction with information, awareness-raising and practical workshops and classes aimed at educating and supporting new mothers (e.g., baby massage classes, weaning workshops, paediatric first aid, dental health and child safety) (See Table 1). Other supports are offered to parents at later junctures in the child's developmental progression including tailor-made play workshops, oral language development supports, a healthy eating workshop and/or the Incredible Years Parent and Toddler Programme (IYPTP) [39]. The overarching aim of this new service model is to provide appropriate education and supports to improve parent competency and well-being, strengthen parent-child relationships and enhance child developmental outcomes.

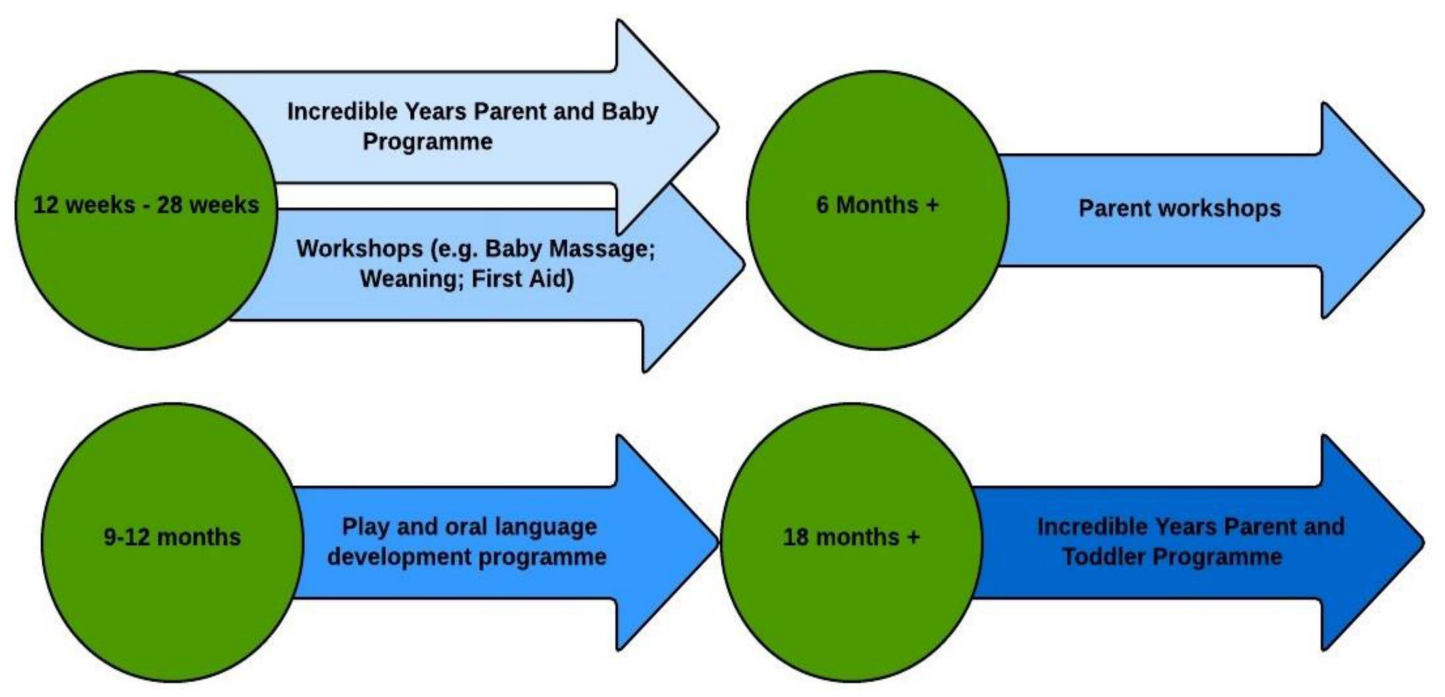

Figure 1. Outline of the Parent and Infant Programme. 
Table 1. Parent and Infant Program Components, Core Topics and Objectives.

\begin{tabular}{|c|c|c|}
\hline Components & Core Topics & Objectives \\
\hline $\begin{array}{l}\text { Incredible Years Parent and Baby } \\
\text { programme } \\
\text { (8 sessions) }\end{array}$ & $\begin{array}{l}\text { Getting to know your baby } \\
\text { Babies as intelligent learners } \\
\text { Providing physical, tactile and visual stimulation } \\
\text { Parents learning to read babies' minds } \\
\text { Gaining support } \\
\text { Babies' emerging sense of self }\end{array}$ & $\begin{array}{l}\text { - Strengthen parent knowledge and self-confidence through learning about babies' } \\
\text { development and developmental milestones } \\
\text { - Enhance parent-infant relationships and parental competencies, prevent infant } \\
\text { maladjustment and promote infant wellbeing through skills and techniques to support } \\
\text { learning and development and healthy behaviours (feeding, sleeping, calming babies) } \\
\text { - Empower parents through learning about self-care and gaining support }\end{array}$ \\
\hline $\begin{array}{l}\text { Baby Massage } \\
(4 \text { sessions })\end{array}$ & $\begin{array}{l}\text { Relief-Colic and wind; Emotional stress } \\
\text { Relaxation—Soothes and aids sleep } \\
\text { Stimulation-Build immunity and help gain weight } \\
\text { Interaction-Aid bonding and reduce postnatal depression }\end{array}$ & $\begin{array}{l}\text { - Enhance parent-infant bonding and alleviate infant stress } \\
\text { Promote parental sense of competence and well-being } \\
\text { (e.g., reduce postnatal depression) }\end{array}$ \\
\hline $\begin{array}{l}\text { Weaning workshop } \\
\text { (1 session) }\end{array}$ & $\begin{array}{l}\text { Stages of weaning, timing, quantities, feeding techniques } \\
\text { Food safety and hygiene } \\
\text { Healthy eating principles } \\
\text { Practical cookery demonstration and advice }\end{array}$ & $\begin{array}{l}\text { - Enhance parents' knowledge/competencies in relation to healthy eating } \\
\text { - Increase healthy eating behaviors } \\
\text { Prevent early weaning }\end{array}$ \\
\hline $\begin{array}{l}\text { Paediatric First Aid workshop } \\
\text { (1 session)/Child safety } \boldsymbol{t}(1 \text { session })\end{array}$ & $\begin{array}{l}\text { Child resuscitation } \\
\text { Dealing with injury, poisoning, choking and medical emergencies } \\
\text { Recovery position } \\
\text { Threats to child safety and child proofing home environments }\end{array}$ & $\begin{array}{l}\text { Prevent/Reduce incidents of injury to infants through parents learning first aid skills } \\
\text { and baby-proofing home/environments techniques; and } \\
\text { Enable parents (promote sense of competence) to identify, remove and } \\
\text { respond to threats }\end{array}$ \\
\hline $\begin{array}{l}\text { Returning to work workshop } \\
\text { (1 session) }\end{array}$ & $\begin{array}{l}\text { Information on childcare options } \\
\text { Guidelines for choosing childcare }\end{array}$ & - Empower parents/reduce parental anxiety in relation to returning to work \\
\hline $\begin{array}{l}\text { Active Playt }(2 \text { sessions }) / \text { Play \& Oral } \\
\text { Language Development program * } \\
(4 \text { sessions) }\end{array}$ & $\begin{array}{l}\text { Play skills and strategies } \\
\text { Language development milestones } \\
\text { Practical play sessions and advice }\end{array}$ & $\begin{array}{l}\text { - Strengthen parent knowledge and competencies through playing skills and strategies } \\
\text { - Enhance parent-child relationships and encourage child wellbeing through play } \\
\text { Promote child language development and pre-literacy skills }\end{array}$ \\
\hline $\begin{array}{l}\text { Incredible Years Parent and } \\
\text { Toddler Programme } \\
\text { (8 sessions) }\end{array}$ & $\begin{array}{l}\text { Child directed play promotes positive relationships } \\
\text { Promoting toddler's language with child directed coaching } \\
\text { Social and Emotion coaching } \\
\text { The art of praise and encouragement } \\
\text { Spontaneous incentives for toddlers } \\
\text { Handling separations and reunions } \\
\text { Positive discipline-effective limit setting } \\
\text { Positive discipline-handling misbehavior }\end{array}$ & $\begin{array}{l}\text { - Strengthen parent knowledge and self-confidence through learning about } \\
\text { toddler development } \\
\text { Enhance parent-infant relationships and parental competencies, prevent child } \\
\text { maladjustment and promote socioemotional wellbeing (e.g. self-regulation and } \\
\text { self-esteem) through building parent' coaching/modelling skills and play skills } \\
\text { and strategies } \\
\text { - Promote child language development and pre-literacy skills }\end{array}$ \\
\hline
\end{tabular}

+ Delivered in Site 2 Drogheda/Dundalk only; * Delivered in Site 1 West Dublin only. 
The PIN programme is intended to be delivered collaboratively through the usual primary health care and community-based services. Practitioners who are responsible for the 'on the ground' delivery of the intervention are drawn from a pool of community-based services including: Public Health Nurses (PHNs); Family Support Workers; local health officers and Community Development workers. The service model is currently being implemented in two separate sites in the Republic of Ireland, West Dublin and Drogheda/Dundalk, Co. Louth (Northeast Ireland). Both are large urban areas which include neighbourhoods characterised by socioeconomic disadvantages [40]. The development and implementation of the PIN programme is overseen in each site by a multi-disciplinary consortium of local stakeholders (e.g., local PHNs and service providers) called the Blue Skies Initiative in West Dublin and the Genesis Programme in Drogheda/Dundalk.

The delivery of the PIN programme is funded through the "Area Based Childhood" (ABC) programme, an initiative funded by the Irish Government and a former philanthropic organisation (the Atlantic Philanthropies), which involves the implementation of 13 area-based approaches/initiatives to preventing and reducing child poverty in socially deprived areas of Ireland [41]. In both sites, a small number of staff members (e.g., programme coordinators) whose role is to support participant recruitment and engagement, service coordination and service delivery, are employed by the consortia funded through the $\mathrm{ABC}$ programme. A large-scale evaluation of the PIN service model began in 2014 as part of larger research programme called ENRICH (EvaluatioN of wRaparound in Ireland for CHildren and families). This multi-method evaluation is designed to explore the effectiveness and cost-effectiveness of the PIN intervention [42] and involves a controlled trial evaluation. In total, 190 parents were recruited to one of two groups: 106 parents took part in a PIN intervention group, whilst 84 parents were recruited to a 'services as usual' control group. A battery of psychometric and observational measures was used to assess the impact of the PIN programme on parenting competence and parental wellbeing, as well as parent-infant relationships and child development. Assessments were conducted at baseline (prior to the delivery of the PIN programme) and subsequently when infants were 8, 16 and 24 months old.

Early findings from this stage of the controlled trial evaluation (when infants are 8 months old) suggest that PIN programme attendance can benefit parenting self-efficacy as well as the levels of cognitive stimulation and emotional support in the home [43]. However, these findings represent only the first phase of an ongoing and longer-term intervention and evaluation, and parents continue to be offered supports currently. Detecting preventative outcomes may require a longer time frame. It is also important to note that the inherent complexity and multi-dimensionality of these kinds of collaborative, area-based early interventions, present significant challenges for their appraisal and it is crucial, therefore, to monitor and assess the processes involved in their implementation over time in order to gain a fuller understanding of how, and why, particular interventions or services lead to certain outcomes [44]. In this context, implementation, processes and outcomes are important [45]. Indeed, they serve as crucial intermediate outcomes which can provide useful preliminary indicators of programme and/or service success. A new innovation/service will not be effective if it is not implemented successfully [46]. Programmes which are acceptable to, and adopted by, key stakeholders, and which are feasible to implement with fidelity are more likely to yield preventative benefits over the longer run [47]. For this reason, a systematic process evaluation is being conducted in tandem with this controlled trial to examine the implementation of the PIN programme and the contextual factors that influence or shape its delivery and effectiveness [48]. The design of this process evaluation is informed by the 2014 Medical Research Council (MRC) framework for process evaluations [49]. In line with this framework, we aimed to document, in detail, the design of the PIN programme and to outline the key resources, processes and activities involved in the development and installation of the service model within the local community. Two key qualitative data sources were used to develop an in-depth understanding of the development of the PIN programme, including: 
1. A documentary review incorporating programme manuals, $(\mathrm{n}=4)$; implementation protocols and details $(n=3)$; delivery materials $(n=7)$; materials/handouts for parents $(n=9)$; the minutes from implementation team meetings $(n=12)$; the minutes from meetings between the research team and PIN programme implementers $(n=20)$; and reports/presentations produced by PIN programme developers $(n=4)$.

2. Semi-structured interviews with key informants $(n=19)$ recruited from the range of agencies/organisations involved in programme implementation (including community-based services and public health nursing and primary care services). Participants included personnel involved in program development and set-up, implementation planning and support/facilitation, and/or programme delivery including community-based service managers $(n=4)$, Public Health Nurses and Nurse Managers $(n=6)$, family support workers and community-based practitioners $(\mathrm{n}=9)$.

Data were subjected to a thematic content analysis which aimed to capture the activities, inputs, outputs, processes and resources involved in the design, development and establishment of the PIN programme.

\section{Results}

Two findings are presented in two main sections: (1) the development of the PIN programme; and (2) the installation of the service model. Three key themes, and three additional subthemes, were identified which relate to the core implementation activities, processes, organisational features, resources and structures which were important to the design and 'bedding down' of the PIN programme in the local community. These include (a) data gathering and piloting; (b) relationship building; and (c) creating a hospitable environment for innovation and implementation, whilst subthemes relate to the importance of strategic leadership, scaffolding practice change through training, education and support and organisational and resource development for promoting innovation in parent education services.

\subsection{Development of the Parent and Infant Programme}

Data Gathering and Piloting

The first phase in the development of the PIN programme involved an assessment and analysis of parent-infant needs and service provision at the level of the community for the target population, as well as programme piloting. Formal and informal evidence from the empirical literature and the local communities (e.g., surveys, research studies, feedback from parents and practitioners) indicated that children in the area were at greater risk of poorer developmental outcomes including increased risk of injury and poor physical health; socioemotional and behavioural problems, and poorer educational outcomes. Feedback from families participating in existing stand-alone IY programmes indicated that parenting difficulties in later childhood are often preceded by a history of interactional problems stemming from infancy/early parenthood, as well as a struggle to cope with the transition to parenthood and a sense of isolation in the parental role. Parent reports also highlighted a demand for parenting supports in the earliest years.

Subsequently, the IY parent and baby programme was piloted by Archways in West Dublin with 43 first-time mothers and their infants [50]. The findings indicated high levels of parent engagement and satisfaction. Measures of parent wellbeing, parenting satisfaction and stress taken before and after programme participation, as well as qualitative interviews, provided tentative evidence of the potential utility and benefits of the IYPBP for improving parenting outcomes in early infancy. Nevertheless, the feedback from parents also further reinforced the multiple needs of new parents and infants. An expeditious audit of local services/organisations, which was conducted in parallel, highlighted that whilst a wide variety of supports for new parents were available at the local level, gaps in service delivery, a lack of joined up service provision and barriers to access for parents were also noted. 
Nevertheless, established links between Archways and a range of local services (e.g., Family Resource Centres, early childhood education settings, social work services and Public Health Nursing services) provided a unique opportunity to develop a more collaborative, interdisciplinary and multimodal intervention process.

At the same time, the Springboard Initiative (formerly a community initiative with aimed to provide integrated family supports) and the Genesis Programme in Louth also piloted the IY Parent and Baby Programme which resulted in similar indicators of parent benefits. Local parent and service needs were also assessed and the programme was customised to meet specific community needs and local service delivery capacities. Overall, this process of needs analysis and information gathering highlighted multiple needs of disadvantage families; the importance of early, preventative interventions; and the potential utility of joined-up/collaborative approaches to reduce gaps in service delivery and tackle barriers to disengagement. In turn, this provided an impetus for the development of an early parenting intervention which would be provided on a community-wide, universal basis. It was hoped that this service model would: (i) act as a primary prevention strategy through the use of group-based parenting education and supports; (ii) provide a range of supports which were developmentally tailored to the needs of new parents and their infants; (ii) address multiple risk factors; (iii) involve collaboration between key multi-disciplinary stakeholders to tailor service delivery to child/family/community needs; (iv) tackle gaps in treatment; and (v) address barriers to engagement for 'harder to reach' families.

Thus, programme developers sought out the participation of multidisciplinary practitioners to partner in the delivery of this new service model, including Public Health Nurses (PHNs), family support workers, parent/community-based volunteers and community health officers. The PIN programme content was subsequently identified which, as outlined above, brought together a standardised parent training/education model with a range of 'wraparound' community-based developmentally-tailored supports. This model was developed to promote holistic parenting support and greater integration of health and community care sectors, such as nutrition, education, child and family welfare. In line with the philosophy of wraparound intervention, there are a small number of differences in the content and process of delivery between the West Dublin and Louth sites which reflect the differing needs of community members in these areas (see Table 1).

\subsection{Installation of the PIN Programme}

Relationship Building

The introduction of innovations of practice and service delivery involves a complex process and resistance to such change is not uncommon [35,51]. Thus, a relationship building process was initiated at the local level to overcome any potential resistance to change and programme implementation, aimed at garnering support for innovation. In particular, securing the support and co-operation of the local Public Health Nursing (PHN) service was identified as crucial to the successful initiation of PIN programme implementation. Substantial differences between routine PHN service delivery and PIN programme implementation were recognised including the move to a group-based, facilitative-collaborative model of service delivery. The introduction of this innovative new model required not just cross agency partnerships, but also close collaboration with parents. In line with the parent education approach inherent in the Incredible Years suite of interventions, the PIN programme utilises a collaborative, facilitative approach to programme delivery, whereby parent skill development and learning is promoted through a problem-solving approach, operationalised through parent-led discussions and role playing. Thus, group discussions are incorporated to help parents identify positive/beneficial aspects of their own approach to family/child nutrition, as well as areas which they could improve. This non-didactic, peer-led approach is focused on educating and empowering parents by participating and engaging in a group process to develop their own solutions to 
parenting challenges, thereby developing parenting skills and fostering coping skills and self-efficacy in parents.

One PHN involved in this innovation (and who took part in our series of stakeholder interviews) noted:

"I was very, very interested [in delivery], and a bit overwhelmed, when we went to the training because it was completely out of our comfort zone. As a Public Health Nurse, you are all the time giving information, trying to solve the problems, fix people's problems, make it better, and this is a sort of a situation where you sit back and facilitate".

The above statement illustrates how the prospect of practice change can be daunting for practitioners working at the coalface of programme delivery, but also how the introduction of a new initiative requires not just training and capacity development for individual practitioners, but also a change in attitude and values, as well as a cultural shift within organisations. For this reason, local community-based organisations involved in developing the PIN programme, invested considerable efforts in relationship building and partnership working in order to overcome potential resistance to innovation. This approach was aimed at uncovering key stakeholder concerns around the implementation of the new programme. Programme developers placed an emphasis on recognising and respecting the expertise of partners, as well as understanding the limitations/boundaries within which key stakeholders provided services to children and families. A flexible, transparent and problem-solving perspective was seen by programme developers as critical to uncovering and addressing stakeholder fears and potential challenges vis-a-vis their involvement in programme delivery and helping to overcome barriers to such involvement. There was also a recognition of the importance of ensuring a 'fit' between the intervention and the priorities of local stakeholders in order to facilitate implementation. The process of promoting buy-in to innovation and collaboration, was supported by involving implementation partners in the development and planning process, thereby aligning the PIN programme and its aims and objectives, with the priorities and values of participating organisations. Importantly, this form of partnership working helped to develop a common vision and commitment to the implementation of the PIN programme amongst key stakeholders.

Creating a Hospitable Environment for Innovation and Implementation

It is increasingly recognised that for programmes and practices to be effective, a fit between those innovations and the systems in which they are to be implemented, is vital [31,52]. 'Appropriateness' refers to the perceived compatibility between an innovation and the implementation setting [53]. The perceived fit between implementation settings and EBPs is particularly pertinent to the early stages of the implementation process and may influence considerably the extent to which effective programmes are adopted $[35,54]$. Thus, programme adaptation, as well as accommodations within the environment in which programmes are to be implemented, are both necessary to enable intervention delivery and to ensure that interventions are delivered in an effective and efficient manner. Therefore, it is crucial to address intervention-setting compatibility to increase the likelihood of implementation success [18]. Below, we identify key enablers or 'core implementation drivers' [55] which were essential to creating a hospital environment for the implementation of the PIN programme within the local community.

\section{Subtheme 1: Strategic Leadership}

Community leadership was vital to securing a commitment to, and generating buy-in for, installation and implementation. Indeed, several key forms of leadership were identified:

- Programme developers who are locally-based service providers with a track record of evidence-based service provision. 
These programme developers (i.e., Archways/the Genesis Programme) played a lead role in identifying population (parent and infant) needs, identifying evidence-based intervention programmes and processes/services to meet community needs, bringing key stakeholders together in the intervention development process and initiating a planning process for programme installation and implementation.

- Initiators such as stakeholders who held strategic/management positions within local systems and services (e.g., directors within PHN service; managers of community-based services).

Importantly, initiators were those with an ability to clear the pathway to implementation by ensuring that resources were made available for, and removing barriers to implementation (e.g., organisational policies and infrastructures), thereby helping to align programme implementation with the local context. Initiators were also key to encouraging/enabling the involvement of others in innovation, and in particular implementation. Thus, initiators were critical to the availability of human resources/personnel for programme implementation. Programme developers played a key role in identifying and bringing initiators into the process of development and installation.

- Prime movers or key actors including practitioners/personnel who were identified and selected by initiators as having an interest in, commitment to, and the appropriate skills for innovation and programme delivery.

This process of staff selection was important in reducing resistance to initial implementation and ensuring the presence of effective practitioners to support implementation during the early stages of programme delivery. Overall, the different forms of leadership outlined above, and the ways in which they developed and operated in the context of the PIN programme development, were important in providing a solid foundation for the successful installation and implementation of the programme.

Subtheme 2: Scaffolding change-training, education and support

The approach to the installation of the PIN programme can be characterised as a graduated approach which aimed to gently introduce innovation of practice to prime movers. Importantly, initiators recognised the significant change in practice required for collaborative programme implementation. Several activities, therefore, were undertaken to support the initiation of innovation within the local service setting, namely training/education and supplementary technical support. These included the following:

(i) Training to support behavioural and practice change delivered to key stakeholders (e.g., a 2-day training session in the Incredible Years Parent and Baby/Parent and Toddler Programme) to provide practitioners with delivery skills.

(ii) Formal coaching for practitioners to support 'on the job' learning; this was available between programme sessions and provided reflective assessment and feedback on delivery performance.

(iii) Providing peer support for practitioners who were implementing aspects of the programme for the first time; this involved pairing newly trained practitioners with more experienced facilitators thereby providing access to technical, as well as 'moral' or emotional support throughout the implementation process (i.e., by addressing the fear of the unknown).

(iv) Ensuring participation in programme delivery by making available programme materials/resources for implementers. Thus, the burden on practitioners was reduced by removing the need for those involved in programme delivery to deal with 'administrative' aspects of programme delivery (e.g., photocopying, printing, etc.).

\section{Subtheme 3: Organisational and resource development}

Implementation Teams (ITs) are increasingly understood to be a key aspect of successful implementation [56,57]. Such teams are typically multidisciplinary and bring together key stakeholders 
from a range of organisations involved in programme delivery; they provide a vehicle for supporting programme providers. Within the context of the PIN programme, an IT was established to oversee and monitor programme delivery and implementation; respond to barriers/challenges to programme delivery; develop plans/protocols for programme implementation and delivery; promote programme embedding within local settings; gather and analyse data on delivery; lead on implementation decision making; and advise the overall strategy of programme implementation. The IT also provided a forum for communication between key stakeholders involved in programme implementation whilst also enabling and promoting collaborative, interdisciplinary programme delivery. Importantly, the IT brings key decision makers/strategic leaders into the programme implementation planning process. This enables a process of information gathering regarding the programme delivery and a process of performance assessment, which is, in turn, used to inform programme planning. Furthermore, the IT also involves local stakeholders who are in a strategic position to assess the feasibility of programme implementation plans vis-à-vis the adaptive systems within which delivery occurs, and/or to address the availability/redistribution of resources to facilitate/remove barriers to programme implementation.

In both sites where the PIN programme is being delivered, a small number of staff members are also in place to support participant recruitment and engagement, service coordination and service delivery. Specifically, these roles include (i) a Project Manager and (ii) a Support and Engagement Officer. The former supports the coordination and deployment of implementation resources (e.g., hiring venues, organising and sharing programme materials, photocopying, and managing equipment), coordinates, communicates and liaises with practitioners/implementers for parent recruitment and programme delivery, coordinates the timing and delivery of programme components, supports implementation processes and organises planning meetings and the development of implementation protocols. The Support and Engagement Officer, on the other hand, liaises with practitioners on recruitment, coordinates recruitment processes, gathers and maintains contact details for recruited parents, liaises with parents on programme delivery and promotes parent engagement.

\section{Discussion}

Investment in early years parenting support and early child development is an increasingly important feature of international policies and strategies to reduce poverty and inequality and enhance human capital and wellbeing [58]. The PIN programme is a novel early parenting education and support intervention which offers comprehensive, group-based services to parents and infants within a 2-year delivery cycle and which aims to promote joined up, interagency service delivery on a universal, community-wide basis.

Our results suggest that a number of key factors influenced the development and installation of this collaborative service model at a local level, including a combination of skills, resources and organisational/infrastructural drivers. The use of needs assessment and local knowledge and skills to inform the development of the PIN programme, and to build a platform for initial implementation, were important implementation drivers. The provision of scaffolds and supports for innovation and change in practice, were also crucial to the successful installation of the programme, whilst collaborative practice was an additional notable feature of the exploration and installation process. Significantly, these findings illustrate that the use of a programme planning approach - which was characterised by data gathering, relationship building and capacity and support development-was central to generating and harnessing leadership, commitment, motivation and buy-in for implementation, whilst at the same time providing an appropriate technical skills base for programme delivery. Finally, developing infrastructural/organisational and administrative support were also important in establishing the programme within the local community.

This case example of the development and setting up of the Irish PIN programme, highlights the importance of appropriate groundwork and preparation in establishing the collaborative implementation of a prevention and early intervention initiative. Overall, the results reported here highlight the importance of fostering a hospitable, facilitative climate in order to support 
and enable interagency working. Partnership working and collaborative planning and negotiation from the outset of programme development and throughout implementation, are also crucial to supporting interagency-focused innovation efforts. Other factors which emerged from our findings as fundamental to this process, include a respect and recognition for partners' capacities, limitations and potentially conflicting priorities, as well as appropriate resources, protocols, scaffolds and skill building supports. Importantly, this kind of community-based research can play a crucial role in informing decision making in the public health sector and in helping to shape public policy.

The collaborative implementation of prevention and early intervention efforts is a cornerstone of many public health policies in numerous countries throughout the EU [59], including Ireland [60] and the UK [61], and is increasingly recognised as best practice in children's services. However, there are persistent challenges to developing, establishing and sustaining the collaborative delivery of evidence-based parenting interventions and early child development supports [62]. Further research, coupled with effective and timely practice and policy developments and innovations, is needed to address these challenges. For example, further evidence on the effectiveness of coordinated services is required [63], whilst we still have much to learn about the experiences of practitioners, decision makers and services involved in collaborative prevention and early intervention interagency initiatives, as well as the barriers to, and facilitators of, effective and evidence-based joined-up service delivery. The ENRICH research programme, which incorporates a detailed impact and process evaluation, will provide important information about the implementation, effectiveness and cost-effectiveness, of a collaborative model of service provision for parents and infants. The research is also beginning to generate valuable insights, such as those presented here, into the factors which can facilitate or impede programme implementation and effectiveness. Thus, this research forms part of a larger goal to provide evidence on both programme effectiveness and implementation, as well as exploring the relationship between implementation and the impact of complex early intervention programmes on parents and their children.

\section{Conclusions}

Effective support and education for parents and children, particularly during the first 1000 days, is an important public health priority [64]. Parents who are knowledgeable about child development and effective childrearing practices are more likely to feel a greater sense of competency in their parenting role and to respond more appropriately and sensitively to their young children [4]. Prevention and early intervention initiatives which are evidence-based and holistic in nature can help to prevent developmental inequality and result in substantial social and economic benefits $[10,14]$. High-quality implementation, involving coordinated, collaborative efforts which create cross agency supports but also involve parents in an active and engaged manner, are necessary to build capacity within children's services and potentially improve outcomes for children [65]. It is imperative, in the context of increasing commitment to public investment in child and family services, that research is conducted to provide decision makers and services providers with practical information on how complex, collaborative intervention strategies can be embedded within usual care settings for parents and their very young children. Future research should explore what constitutes best practice in terms of collaborative early parenting intervention and support, including the impact on family outcomes as well as implementation processes, practices and strategies. More research is also needed to build an understanding of the resources, scaffolds and plans required for the scale-up of evidence-based, collaborative parenting supports. Lastly, effective partnerships are required not only across services, but involving all stakeholders including service providers, parents, researchers and policy makers alike. These kinds of partnerships can help to build an evidence-base to demonstrate what works best for parents and infants and under what circumstances, as well as informing and educating those who work at the frontline of service provision. 
Author Contributions: Conceptualization, G.H. and S.M.; Methodology, G.H. and S.M.; Writing-Original Draft Preparation, G.H., S.M., Y.L. and A.S.; Writing-Review \& Editing, G.H., S.M., Y.L. and A.S.; Project Administration, Y.L.; Funding Acquisition, S.M.

Funding: This research is funded by the Health Research Board in Ireland through its (five-year) 'Collaborative Applied Research Grants scheme in Population Health and Health Services Research 2012' which was awarded to SMcG as the Principal Investigator (CARG/2012/17).

Conflicts of Interest: The authors declare no conflict of interest.

\section{References}

1. Chan, M.; Lake, A.; Hansen, K. The early years: Silent emergency or unique opportunity? Lancet 2017, 389, 11-13. [CrossRef]

2. Black, M.M.; Walker, S.P.; Fernald, L.C.; Andersen, C.T.; DiGirolamo, A.M.; Lu, C.; McCoy, D.C.; Fink, G.; Shawar, Y.R.; Shiffman, J.; et al. Early childhood development coming of age: Science through the life course. Lancet 2017, 389, 77-90. [CrossRef]

3. Britto, P.R.; Lye, S.J.; Proulx, K.; Yousafzai, A.K.; Matthews, S.G.; Vaivada, T.; Perez-Escamilla, R.; Rao, N.; Ip, P.; Fernald, L.C.; MacMillan, H. Nurturing care: Promoting early childhood development. Lancet 2017, 389, 91-102. [CrossRef]

4. $\quad$ Bornstein, M.H.; Cote, L.R.; Haynes, O.M.; Hahn, C.-S.; Park, Y. Parenting knowledge: Experiential and sociodemographic factors in european american mothers of young children. Dev. Psychol. 2010, 46, 1677-1693. [CrossRef] [PubMed]

5. Bornstein, M.H. Determinants of Parenting. In Developmental Psychopathology; Wiley: Hoboken, NJ, USA, 2015; pp. 180-270.

6. Landry, S.H.; Smith, K.E.; Swank, P.R.; Guttentag, C. A responsive parenting intervention: The optimal timing across early childhood for impacting maternal behaviors and child outcomes. Dev. Psychol. 2008, 44, 1335-1353. [CrossRef] [PubMed]

7. Leijten, P.; Raaijmakers, M.A.; Orobio de Castro, B.; van den Ban, E.; Matthys, W. Effectiveness of the Incredible Years Parenting Program for families with socioeconomically disadvantaged and ethnic minority backgrounds. J. Clin. Child Adolesc. Psychol. 2017, 46, 59-73. [CrossRef] [PubMed]

8. Love, J.M.; Kisker, E.E.; Ross, C.; Raikes, H.; Constantine, J.; Boller, K.; Brooks-Gunn, J.; Chazan-Cohen, R.; Tarullo, L.B.; Brady-Smith, C.; et al. The effectiveness of early head start for 3-year-old children and their parents: Lessons for policy and programs. Dev. Psychol. 2005, 41, 885-901. [CrossRef] [PubMed]

9. Pinquart, M.; Teubert, D. Effects of parenting education with expectant and new parents: A meta-analysis. J. Fam. Psychol. 2010, 24, 316. [CrossRef] [PubMed]

10. Van Zeijl, J.; Mesman, J.; Van IJzendoorn, M.H.; Bakermans-Kranenburg, M.J.; Juffer, F.; Stolk, M.N.; Koot, H.M.; Alink, L.R.A. Attachment-based intervention for enhancing sensitive discipline in mothers of 1- to 3-year-old children at risk for externalizing behavior problems: A randomized controlled trial. J. Consult. Clin. Psychol. 2006, 74, 994-1005. [CrossRef] [PubMed]

11. Campbell, F.A.; Pungello, E.P.; Burchinal, M.; Kainz, K.; Pan, Y.; Wasik, B.H.; Barbarin, O.A.; Sparling, J.J.; Ramey, C.T. Adult outcomes as a function of an early childhood educational program: An abecedarian project follow-up. Dev. Psychol. 2012, 48, 1033-1043. [CrossRef] [PubMed]

12. Campbell, F.; Conti, G.; Heckman, J.J.; Moon, S.H.; Pinto, R.; Pungello, E.; Pan, Y. Early childhood investments substantially boost adult health. Science 2014, 343, 1478-1485. [CrossRef] [PubMed]

13. Kitzman, H.; Olds, D.L.; Sidora, K.; Henderson, C.R., Jr.; Hanks, C.; Cole, R.; Luckey, D.W.; Bondy, J.; Cole, K.; Glazner, J. Enduring effects of nurse home visitation on maternal life course. JAMA 2000, $283,1983$. [CrossRef] [PubMed]

14. Heckman, J.J.; Moon, S.H.; Pinto, R.; Savelyev, P.A.; Yavitz, A. The rate of return to the highscope perry preschool program. J. Public Econ. 2010, 94, 114-128. [CrossRef] [PubMed]

15. O'Neill, D.; McGilloway, S.; Donnelly, M.; Bywater, T.; Kelly, P. A cost-effectiveness analysis of the incredible years parenting programme in reducing childhood health inequalities. Eur. J. Heal. Econ. 2011, 14, 85-94. [CrossRef] [PubMed]

16. Machel, G. Good early development-The right of every child. Lancet 2017, 389, 13-14. [CrossRef] 
17. Proctor, E.K.; Powell, B.J.; McMillen, J.C. Implementation strategies: Recommendations for specifying and reporting. Implement. Sci. 2013, 8, 139. [CrossRef] [PubMed]

18. Waltz, T.J.; Powell, B.J.; Matthieu, M.M.; Damschroder, L.J.; Chinman, M.J.; Smith, J.L.; Proctor, E.K.; Kirchner, J.E. Use of concept mapping to characterize relationships among implementation strategies and assess their feasibility and importance: Results from the Expert Recommendations for Implementing Change (ERIC) study. Imp. Sci. 2015, 10, 109-117. [CrossRef] [PubMed]

19. Novins, D.K.; Green, A.E.; Legha, R.K.; Aarons, G.A. Dissemination and implementation of evidence-based practices for child and adolescent mental health: A systematic review. J. Am. Acad. Child Adolesc. Psychiatry 2013, 52, 1009-1025. [CrossRef] [PubMed]

20. Darlington, Y.; Feeney, J.A.; Rixon, K. Interagency collaboration between child protection and mental health services: Practices, attitudes and barriers. Child Abuse Negl. 2005, 29, 1085-1098. [CrossRef] [PubMed]

21. Iachini, A.L.; DeHart, D.D.; McLeer, J.; Hock, R.; Browne, T.; Clone, S. Facilitators and barriers to interagency collaboration in mother-child residential substance abuse treatment programs. Child. Youth Serv. Rev. 2015, 53, 176-184. [CrossRef]

22. Johnson, P.; Wistow, G.; Schulz, R.; Hardy, B. Interagency and interprofessional collaboration in community care: The interdependence of structures and values. J. Interpress. Care 2003, 17, 70-83. [CrossRef]

23. Warmington, P.; Daniels, H.; Edwards, A.; Brown, S.; Leadbetter, J.; Martin, D.; Middleton, D. Interagency Collaboration: A Review of the Literature; Learning in and for Interagency Working Project: Bath, UK, 2004.

24. hsien Tseng, S.; Liu, K.; Wang, W.-L. Moving toward being analytical: A framework to evaluate the impact of influential factors on interagency collaboration. Child. Youth Serv. Rev. 2011, 33, 798-803. [CrossRef]

25. Mullin, M.; Daley, D.M. Working with the state: Exploring interagency collaboration within a federalist system. J. Public Adm. Res. Theory 2009, 20, 757-778. [CrossRef]

26. Duggan, C.; Corrigan, C.; Social, W.R. A Literature Review of Inter-Agency Work with a Particular Focus on Children's Services; Children Acts Advisory Board: Dublin, Ireland, 2009.

27. Van Dongen, T.; Sabbe, B.; Glazemakers, I. A protocol for interagency collaboration and family participation: Practitioners' perspectives on the Client Network Consultation. J. Interprof. Care 2018, 32, 14-23. [CrossRef] [PubMed]

28. Sloper, P. Facilitators and barriers for co-ordinated multi-agency services. Child Care Health Dev. 2004, 30, 571-580. [CrossRef] [PubMed]

29. Wong, S.; Sumsion, J. Integrated early years services: A thematic literature review. Early Years 2013, 33, 341-353. [CrossRef]

30. Atkinson, M.; Jones, M.; Lamont, E. Multi-Agency Working and Its Implications for Practice; CfBT Education Trust: Reading, UK, 2007.

31. Cooper, M.; Evans, Y.; Pybis, J. Interagency collaboration in children and young people's mental health: A systematic review of outcomes, facilitating factors and inhibiting factors. Child. Care Health Dev. 2016, 42, 325-342. [CrossRef] [PubMed]

32. Oliver, C.; Mooney, A.; Statham, J. Integrated Working: A Review of the Evidence; Thomas Coram Research Unit, Institute of Education, University of London: London, UK, 2010.

33. Siraj-Blatchford, J. Education for sustainable development in early childhood. Int. J. Early Child. 2009, 41, 9. [CrossRef]

34. Akin, B.A.; Strolin-Goltzman, J.; Collins-Camargo, C. Successes and challenges in developing trauma-informed child welfare systems: A real-world case study of exploration and initial implementation. Child. Youth Serv. Rev. 2017, 82, 42-52. [CrossRef]

35. Hickey, G.; McGilloway, S.; O’Brien, M.; Leckey, Y.; Devlin, M.; Donnelly, M. Strengthening stakeholder buy-in and engagement for successful exploration and installation: A case study of the development of an area-wide, evidence-based prevention and early intervention strategy. Child. Youth Serv. Rev. 2018. [CrossRef]

36. Powell, B.J.; Beidas, R.S.; Lewis, C.C.; Aarons, G.A.; McMillen, J.C.; Proctor, E.K.; Mandell, D.S. Methods to improve the selection and tailoring of implementation strategies. J. Behav. Health Serv. Res. 2017, 44, 177-194. [CrossRef] [PubMed]

37. Webster-Stratton, C.H.; Jamila Reid, M. The Incredible Years Program for children from infancy to pre-adolescence: Prevention and treatment of behavior problems. In Clinical Handbook of Assessing and Treating Conduct Problems in Youth; Springer: New York, NY, USA, 2011; pp. 117-138. 
38. Available online: http://www.incredibleyears.com/programs/parent/babies-curriculum/ (accessed on 19 October 2018).

39. Available online: http://www.incredibleyears.com/programs/parent/toddler-curriculum/ (accessed on 19 October 2018).

40. Haase, T.; McKeown, K. Developing Disadvantaged Areas through Area-Based Initiatives: Reflections on Over a Decade of Local Development Strategies; Area Development Management: Dublin, Ireland, 2003.

41. Department of Children and Youth Affairs. Area Based Childhood Programme. 2013. Available online: https:/ / www.dcya.gov.ie/documents/publications/20170421ABCProgramme2013to2017.pdf (accessed on 10 August 2018).

42. Hickey, G.; McGilloway, S.; Leavy, S.; Leckey, Y.; Furlong, M.; O'Connor, S. ENRICHing Children's Lives in the Earliest Years through the Implementation and Evaluation of new Wraparound Services for Parents and Infants in Disadvantaged Areas. Child. Res. Digest 2015, 2, 54-60.

43. Grainne, H.; McGilloway, S.; Leckey, Y.; Leavy, S.; Stokes, A.; O'Connor, S.; Donnelly, M.; Bywater, T.; Cardwell, C.R. Testing the effectiveness of a universal, preventative, wraparound-inspired, group-based early parenting intervention: An exploratory community-based, controlled trial. (in submission)

44. Moore, G.; Audrey, S.; Barker, M.; Bond, L.; Bonell, C.; Cooper, C.; Hardeman, W.; Moore, L.; O'Cathain, A.; Tinati, T.; et al. Process Evaluation in Complex Public Health Intervention Studies: The Need for Guidance. J. Epidemiol. Community Health 2014, 68, 101-102. [CrossRef] [PubMed]

45. Powell, B.J.; Waltz, T.J.; Chinman, M.J.; Damschroder, L.J.; Smith, J.L.; Matthieu, M.M.; Proctor, E.K.; Kirchner, J.E. A refined compilation of implementation strategies: Results from the expert recommendations for implementing change (Eric) project. Implement. Sci. 2015, 10. [CrossRef] [PubMed]

46. Proctor, E.; Silmere, H.; Raghavan, R.; Hovmand, P.; Aarons, G.; Bunger, A.; Griffey, R.; Hensley, M. Outcomes for implementation research: Conceptual distinctions, measurement challenges, and research agenda. Adm. Policy Ment. Heal. Ment. Health Serv. Res. 2010, 38, 65-76. [CrossRef] [PubMed]

47. Costello, E.J. Early detection and prevention of mental health problems: Developmental epidemiology and systems of support. J. Clin. Child Adolesc. Psychol. 2016, 45, 710-717. [CrossRef] [PubMed]

48. Hickey, G.; McGilloway, S.; Furlong, M.; Leckey, Y.; Bywater, T.; Donnelly, M. Understanding the implementation and effectiveness of a group-based early parenting intervention: A process evaluation protocol. BMC Health Serv. Res. 2016, 16, 490. [CrossRef] [PubMed]

49. Moore, G.F.; Audrey, S.; Barker, M.; Bond, L.; Bonell, C.; Hardeman, W.; Moore, L.; O'Cathain, A.; Tinati, T.; Wight, D.; et al. Process evaluation of complex interventions: Medical Research Council guidance. BMJ 2016, 350, h1258. [CrossRef] [PubMed]

50. Twist, E.; McDonnell, S.; Kennedy, L. The incredible years parent and babies programme: A pilot study in west Dublin. Considerations for future implementation \& social policy. Irish Rev. Community Econ. Dev. Law 2012, 1, 43-62.

51. Cabassa, L.J.; Baumann, A.A. A two-way street: Bridging implementation science and cultural adaptations of mental health treatments. Implement. Sci. 2013, 8. [CrossRef] [PubMed]

52. Aarons, G.A.; Sommerfeld, D.H. Leadership, innovation climate, and attitudes toward evidence-based practice during a statewide implementation. J. Am. Acad. Child Adolesc. Psychiatry 2012, 51, 423-431. [CrossRef] [PubMed]

53. Powell, B.J.; McMillen, J.C.; Proctor, E.K.; Carpenter, C.R.; Griffey, R.T.; Bunger, A.C.; Glass, J.E.; York, J.L. A compilation of strategies for implementing clinical innovations in health and mental health. Med. Care Res. Rev. 2012, 69, 123-157. [CrossRef] [PubMed]

54. Lyon, A.R.; Lau, A.S.; McCauley, E.; Vander Stoep, A.; Chorpita, B.F. A case for modular design: Implications for implementing evidence-based interventions with culturally diverse youth. Prof. Psychol. Res. Pract. 2014, 45, 57-66. [CrossRef] [PubMed]

55. Fixsen, D.L.; Naoom, S.F.; Blase, K.A.; Friedman, R.M. Implementation Research: A Synthesis of the Literature; National Implementation Research Network, University of South Florida: Tampa, FL, USA, 2005.

56. Fixsen, D.L.; Blase, K.A.; Naoom, S.F.; Wallace, F. Core implementation components. Res. Soc. Work Pract. 2009, 19, 531-540. [CrossRef]

57. Hurlburt, M.; Aarons, G.A.; Fettes, D.; Willging, C.; Gunderson, L.; Chaffin, M.J. Interagency collaborative team model for capacity building to scale-up evidence-based practice. Child. Youth Serv. Rev. 2014, 39, 160-168. [CrossRef] [PubMed] 
58. Lo, S.; Das, P.; Horton, R. A good start in life will ensure a sustainable future for all. Lancet 2017, 389, 8-9. [CrossRef]

59. Barnes, J.; Melhuish, E.; Guerra, J.C.; Karwowskastruczyk, M.; Petrogiannis, K.; Wyslowska, O.; Zachrisson, H.D. Interagency coordination of services for children and families-An initial literature review. 2017. Available online: http://isotis.org/wp-content/uploads/2017/04/ISOTIS_D6.1Inter-agency-coordination-of-services-for-children-and-families-Initial-Literature-Review.pdf (accessed on 19 October 2018).

60. Department of Children and Youth Affairs. Better Outcomes, Brighter Futures: The National Policy Framework for Children and Young People 2014-2020. 2014. Available online: https:/ /www.dcya.gov.ie/ documents /cypp_framework/BetterOutcomesBetterFutureReport.pdf (accessed on 19 October 2018).

61. Treasury, H.M. Every Child Matters (Green Paper); H.M. Stationery Office: Norwich, UK, 2003.

62. Hutchings, J.; Elen Williams, M. Joined-up thinking, joined-up services, exploring coalface challenges for making services work for families with complex needs. J. Child. Serv. 2014, 9, 31-41. [CrossRef]

63. Mc McKeown, K. Inter-agency cooperation between services for children and families in Ireland: Does it improve outcomes? J. Child. Serv. 2012, 7, 191-200. [CrossRef]

64. Richter, L.M.; Daelmans, B.; Lombardi, J.; Heymann, J.; Boo, F.L.; Behrman, J.R.; Lu, C.; Lucas, J.E.; Perez-Escamilla, R.; Dua, T.; et al. Investing in the foundation of sustainable development: Pathways to scale up for early childhood development. Lancet 2017, 389, 103-118. [CrossRef]

65. Nores, M.; Fernandez, C. Building capacity in health and education systems to deliver interventions that strengthen early child development. Ann. N. Y. Acad. Sci. 2018, 1419, 57-73. [CrossRef] [PubMed]

(C) 2018 by the authors. Licensee MDPI, Basel, Switzerland. This article is an open access article distributed under the terms and conditions of the Creative Commons Attribution (CC BY) license (http:/ / creativecommons.org/licenses/by/4.0/). 